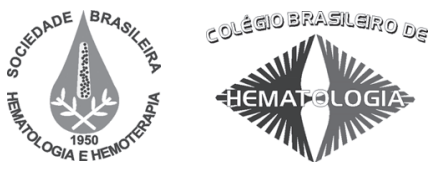

Artigo / Article

\title{
Dez anos de experiência em controle de qualidade em imuno-hematologia
}

\section{Ten years of experience of quality control in immunohematology}

\author{
Marcia C. Z. Novaretti ${ }^{1}$ \\ Silvia L. Bonifácio ${ }^{2}$ \\ Vitor R. Medeiros ${ }^{3}$ \\ Azulamara S. Ruiz ${ }^{4}$ \\ Pedro E. Dorlhiac-Llacer ${ }^{5}$ \\ Dalton A. F. Chamone 6
}

\begin{abstract}
A medicina transfusional tem como objetivo garantir a qualidade e quantidade do sangue, componentes e serviços oferecidos à comunidade, e, dentro desse contexto, a análise dos reagentes imuno-hematológicos é crítica para a realização dos testes pré-transfusionais e, consequentemente, uma transfusão segura. É responsabilidade do controle de qualidade o constante aperfeiçoamento de testes que analisam a qualidade dos reagentes e equipamentos utilizados. Esse trabalho tem por objetivo apresentar os resultados alcançados em dez anos de experiência do Departamento de Controle de Qualidade em Imuno-hematologia da Fundação Pró-Sangue / Hemocentro de São Paulo. No período de janeiro de 1997 a dezembro de 2007 foram realizadas análises em 3.417 reagentes imuno-hematológicos por ocasião da aquisição do reagente e por solicitação de reavaliação (durante o uso). As análises incluíram desde a inspeção visual no recebimento a testes laboratoriais específicos para cada tipo de reagente. Dos 3.417 lotes analisados (média=310/ano, mediana=252/ano), 94 (2,7\%) foram reprovados (média $=8,54 /$ ano, mediana $=7,00 \pm 7,79 /$ ano). Uma vez aprovado pelo controle de qualidade à aquisição, nenhum reagente imunohematológico foi reprovado durante o uso desde 2004. Podemos concluir que, para implementação de um sistema de controle de qualidade de reagentes imuno-hematológicos, não é necessário uso de reagentes ou equipamentos altamente especializados, pois os mesmos são utilizados na rotina laboratorial, como também não envolvem alta complexidade na execução das análises. Podemos enfim considerar que a implementação do controle de qualidade em Imuno-hematologia contribui para o aumento da segurança transfusional e é factivel de realização nos mais diferentes níveis de complexidade dos serviços hemoterápicos. Rev. Bras. Hematol. Hemoter. 2009;31(3):160-165.
\end{abstract}

Palavras-chave: Qualidade; reagentes; hemoterapia; grupos sanguíneos; transfusão.

\section{Introdução}

Há muito se sabe que a padronização de técnicas e especificação de reagentes que envolvem os testes imuno- hematológicos desempenha papel importante para assegurar a garantia da qualidade na medicina transfusional, ${ }^{1}$ sendo responsabilidade de todos os profissionais envolvidos no serviço, o contínuo aprimoramento, validação, adequação das

${ }^{I}$ Médica Hematologista. Chefe da Divisão de Imuno-hematologia da Fundação Pró-sangue/Hemocentro de São Paulo-SP.

${ }^{2}$ Bióloga. Chefe do Depto. de Controle de Qualidade em Imuno-hematologia da Fundação Pró-Sangue/Hemocentro de São Paulo-SP.

${ }^{3}$ Farmacêutico Bioquímico. Biologista do Depto. de Controle de Qualidade em Imuno-hematologia da Fundação Pró-Sangue /Hemocentro de São Paulo-SP.

${ }^{4}$ Biomédica - Biologista do Depto. de Controle de Qualidade em Imuno-hematologia da Fundação Pró-Sangue /Hemocentro de São Paulo-SP.

${ }^{5}$ Professor Livre-docente, Disciplina de Hematologia, Faculdade de Medicina da Universidade de São Paulo - Diretor Técnico Científico da Fundação Pró-Sangue/Hemocentro de São Paulo-SP.

${ }^{6}$ Professor Titular, Disciplina de Hematologia, Faculdade de Medicina da Universidade de São Paulo. Presidente da Fundação Pró-Sangue I Hemocentro de São Paulo-SP. 
especificações técnicas dos reagentes imuno-hematológicos e, sobretudo, a análise dos reagentes recebidos para uso laboratorial. Com o surgimento de implementações dos sistemas de qualidade e de padronizações internacionais, como a criação da ISO 9000 (International Organization for Standardization) em 1987, nasceu a idéia da implementação da garantia de qualidade em bancos de sangue, definindo planejamento e ações que promovam o controle de todo o sistema de processamento do sangue. Nesse contexto, a legislação brasileira, nas últimas décadas, destaca-se quanto ao desenvolvimento de estratégias para avaliação da qualidade dos serviços hemoterápicos. ${ }^{2-6} \mathrm{Na}$ área de Imunohematologia não foi diferente, uma vez que os testes imunohematológicos realizados no sangue do doador e receptor são essenciais e críticos para a realização de uma transfusão segura. ${ }^{7,8}$

$\mathrm{O}$ controle de qualidade interno de reagentes em Imuno-hematologia compreende análise do conteúdo informativo de bulas e rótulos, análises técnicas dos reagentes imuno-hematológicos, como também o constante aperfeiçoamento de testes que analisam a qualidade dos reagentes e equipamentos utilizados nos laboratórios. ${ }^{9,10} \mathrm{~A}$ reavaliação dos reagentes imuno-hematológicos durante o uso contribui para garantia de qualidade do processo transfusional. ${ }^{11}$

Esse trabalho tem por objetivo apresentar os resultados alcançados em dez anos de experiência do Departamento de Controle de Qualidade em Imuno-hematologia da Fundação Pró Sangue/Hemocentro de São Paulo, laboratório com certificação de qualidade ISO 9002 desde 1998, concedida pela British Standards Institution e certificado para a versão ISO 9000:2000, pretendendo dessa forma contribuir para a constante melhoria que a qualidade exige.

A Fundação Pró-Sangue/Hemocentro de São Paulo é um banco de sangue responsável por cerca de $14 \%$ do total de sangue coletado no país. ${ }^{12}$ Por ser uma instituição pública, as aquisições de insumos são feitas a partir de uma descrição técnica por meio de um processo de compras denominado de licitação pública. Nesse processo, empresas que atendam aos requisitos técnicos conforme descrições técnicas e requisitos legais podem apresentar propostas, sendo considerado vencedor aquele que apresentar produto em conformidade com o especificado e menor preço. A elaboração de descrições técnicas detalhadas é de vital importância para a aquisição de reagentes e insumos imuno-hematológicos; para tanto utilizamos diferentes orientações internacionais, e pequenas adaptações foram feitas face a nossa realidade. ${ }^{13,14,15}$

Na Fundação Pró-Sangue/Hemocentro de São Paulo, os reagentes recebidos para avaliação pelo Departamento de Controle de Qualidade em Imuno-hematologia são provenientes de duas origens, por ocasião da aquisição do reagente (prévio a sua utilização) e solicitação de reavaliação interna (durante o uso).

\section{Material e Método}

De janeiro de 1997 a dezembro de 2007 foram avaliados 3.417 reagentes imuno-hematológicos de 56 especificações diferentes, recebidos no Departamento de Controle de Qualidade em Imuno-hematologia da Fundação Pró-Sangue / Hemocentro de São Paulo.

Nesse estudo foram avaliados soros identificadores de antígenos de glóbulos vermelhos: soro anti-A, -B, -AB, - I, $\mathrm{D}$ (monoclonal, policlonal, "blend" e salino), -CDE,-C, -c, -E, $-\mathrm{e},-\mathrm{C}^{\mathrm{w}},-\mathrm{K},-\mathrm{k},-\mathrm{Kp}^{\mathrm{a}},-\mathrm{Kp}^{\mathrm{b}},-\mathrm{Js}^{\mathrm{a}},-\mathrm{Js}^{\mathrm{b}},-\mathrm{Fy}^{\mathrm{a}},-\mathrm{Fy}^{\mathrm{b}},-\mathrm{Jk}^{\mathrm{a}},-\mathrm{Jk}^{\mathrm{b}},-\mathrm{Lu}^{\mathrm{a}}$, $-\mathrm{Lu}^{\mathrm{b}},-\mathrm{Le}^{\mathrm{a}},-\mathrm{Le}^{\mathrm{b}},-\mathrm{Di}^{\mathrm{a}},-\mathrm{M},-\mathrm{N},-\mathrm{S},-\mathrm{s},-\mathrm{P1},-\mathrm{Tj}^{\mathrm{a}},-\mathrm{He},-\mathrm{U},-\mathrm{Wr}^{\mathrm{a}},-\mathrm{Vw}$, $-\mathrm{Xg}^{\mathrm{a}},-\mathrm{Co}^{\mathrm{b}},-\mathrm{Mg},-\mathrm{Co}^{\mathrm{b}}$, reagente controle de $\mathrm{Rh}$, lectinas antiA1 e anti-H, soro antiglobulina humana (monoclonal e policlonal), reagentes anticomplementares anti- $\mathrm{C}_{3 \mathrm{~d}}$ e anti$\mathrm{C}_{3 \mathrm{~b}} \mathrm{C}_{3 \mathrm{~d}}$, reagentes de glóbulos vermelhos (para a pesquisa e identificação de anticorpos irregulares, tipagem $\mathrm{ABO}$ reversa e hemácias sensibilizadas com IgG), e também outros reagentes correlatos, como albumina e solução de polietilenoglicol (P.E.G.).

Em todas as avaliações dos reagentes imunohematológicos, os lotes foram recebidos em embalagem original e, logo após o recebimento, foi realizada inspeção visual, dando ênfase aos seguintes aspectos:

a) Avaliação das condições gerais do reagente à inspeção: rótulo íntegro e firmemente fixado; temperatura de transporte, presença ou ausência de vazamentos, presença ou não de hemólise e partículas estranhas em suspensão, ou em precipitação e turvação.

b) Análise das embalagens externas (que acondicionam a embalagem interna) e internas (que acondicionam o produto), do rótulo (nome correto, uso específico, lote, validade, temperatura de conservação e registro no Ministério da Saúde) e bula com ênfase aos dados informativos de grande relevância, como estar em língua portuguesa e metodologia do teste, conforme disposto pela Agência Nacional de Vigilância Sanitária (Anvisa) e pelo Código de Defesa do Consumidor Brasileiro. ${ }^{2-7,16}$

Depois da inspeção visual, conteúdo informativo da bula e registro no Ministério da Saúde, realizaram-se as análises laboratoriais propriamente ditas. ${ }^{13,14,15-22}$

As características das suspensões de hemácias e requisitos mínimos esperados que foram utilizados nos testes de especificidade, reatividade e título dos soros identificadores de antígenos eritrocitários, controle $\mathrm{Rh}$, antiglobulina humana (monoclonal e policlonal), correlatos (albumina bovina e polietilenoglicol), bem como a inspeção de qualidade dos reagentes de glóbulos vermelhos realizada pelo Departamento de Controle de Qualidade em Imuno-hematologia, foram descritas por Novaretti et al. ${ }^{18}$

Todos os ensaios acima citados são necessários, pois apresentam informações importantes como a especificidade do anticorpo que constitui o produto, a intensidade de reação ocorrida (reatividade) e a potência do reagente (titulação). ${ }^{23}$ 
A análise estatística foi realizada com o uso de testes para análise descritiva e de Mann-Whitney, por meio do software Stata (V.6.0, E.U.A), sendo considerado significante $\mathrm{p}<0,05$.

\section{Resultados}

Observando a Tabela 1 podemos verificar o número de lotes de reagentes recebidos e analisados anualmente no período de janeiro de 1997 a dezembro de 2007 e o total de reagentes aprovados e reprovados. Do total de 3.417 reagentes recebidos, foram analisados em média 310,64 reagentes/ano (mínima $=197$, máxima $=567$, mediana $=252,00$ e d.p. $=115,07)$, dos quais 3.323 reagentes foram aprovados (mínimo=197, máxima=547, mediana=252,00 e d.p.=109,43), o que corresponde a $97,3 \%$, variando de 94,8 a $100 \%$, $\mathrm{p}=0,048$.

Na Tabela 1 são apresentados os números de reagentes analisados aprovados e reprovados (à aquisição e durante o uso) entre 1997 e 2007, onde podemos verificar que o total de reagentes reprovados foi 94 , com 8,5 reagentes reprovados/

\begin{tabular}{|c|c|c|c|c|c|}
\hline \multirow[t]{2}{*}{ Ano } & \multirow{2}{*}{$\begin{array}{l}\text { Total de } \\
\text { inspeções }\end{array}$} & \multirow{2}{*}{$\begin{array}{l}\text { Reagentes } \\
\text { aprovados }\end{array}$} & \multicolumn{3}{|c|}{ Reagentes reprovados } \\
\hline & & & Aquisição & Uso & Total \\
\hline 1997 & 567 & $\begin{array}{c}547 \\
(96,5 \%)\end{array}$ & $\begin{array}{c}17 \\
(2,9 \%)\end{array}$ & $\begin{array}{c}3 \\
0,5 \%)\end{array}$ & $\begin{array}{c}20 \\
(3,5 \%)\end{array}$ \\
\hline 1998 & 210 & $\begin{array}{c}199 \\
(94,8 \%)\end{array}$ & $\begin{array}{c}11 \\
(5,2 \%)\end{array}$ & $\begin{array}{c}0 \\
(0 \%)\end{array}$ & $\begin{array}{c}11 \\
(5,2 \%)\end{array}$ \\
\hline 1999 & 364 & $\begin{array}{c}347 \\
(95,3 \%)\end{array}$ & $\begin{array}{c}13 \\
(3,6 \%)\end{array}$ & $\begin{array}{c}4 \\
(1,1 \%)\end{array}$ & $\begin{array}{c}17 \\
(4,7 \%)\end{array}$ \\
\hline 2000 & 401 & $\begin{array}{c}380 \\
(94,8 \%)\end{array}$ & $\begin{array}{c}21 \\
(5,2 \%)\end{array}$ & $\begin{array}{c}0 \\
(0 \%)\end{array}$ & $\begin{array}{c}21 \\
(5,2 \%)\end{array}$ \\
\hline 2001 & 413 & $\begin{array}{c}406 \\
(98,3 \%)\end{array}$ & $\begin{array}{c}7 \\
(1,7 \%)\end{array}$ & $\begin{array}{c}0 \\
(0 \%)\end{array}$ & $\begin{array}{c}7 \\
(1,7 \%)\end{array}$ \\
\hline 2002 & 311 & $\begin{array}{c}304 \\
(97.7 \%)\end{array}$ & $\begin{array}{c}7 \\
(2,3 \%)\end{array}$ & $\begin{array}{c}0 \\
(0 \%)\end{array}$ & $\begin{array}{c}7 \\
(2,3 \%)\end{array}$ \\
\hline 2003 & 207 & $\begin{array}{c}202 \\
(97,6 \%)\end{array}$ & $\begin{array}{c}1 \\
(0,5 \%)\end{array}$ & $\begin{array}{c}4 \\
(1,9 \%)\end{array}$ & $\begin{array}{c}5 \\
(2,4 \%)\end{array}$ \\
\hline 2004 & 245 & $\begin{array}{c}239 \\
(97,5 \%)\end{array}$ & $\begin{array}{c}6 \\
(2,5 \%)\end{array}$ & $\begin{array}{c}0 \\
(0 \%)\end{array}$ & $\begin{array}{c}6 \\
(2,5 \%)\end{array}$ \\
\hline 2005 & 252 & $\begin{array}{c}252 \\
(100 \%)\end{array}$ & $\begin{array}{c}0 \\
(0 \%)\end{array}$ & $\begin{array}{c}0 \\
(0 \%)\end{array}$ & $\begin{array}{c}0 \\
(0 \%)\end{array}$ \\
\hline 2006 & 197 & $\begin{array}{c}197 \\
(100 \%)\end{array}$ & $\begin{array}{c}0 \\
(0 \%)\end{array}$ & $\begin{array}{c}0 \\
(0 \%)\end{array}$ & $\begin{array}{c}0 \\
(0 \%)\end{array}$ \\
\hline 2007 & 250 & $\begin{array}{c}250 \\
(100 \%)\end{array}$ & $\begin{array}{c}0 \\
(0 \%)\end{array}$ & $\begin{array}{c}0 \\
(0 \%)\end{array}$ & $\begin{array}{c}0 \\
(0 \%)\end{array}$ \\
\hline Total & 3.417 & 3.323 & 83 & 11 & 94 \\
\hline $\mathrm{N} \%$ & $(100 \%)$ & $(97,3 \%)$ & $(2,4 \%)$ & $(0,3 \%)$ & $(2,7 \%)$ \\
\hline Média & 310,64 & 302,09 & 7,54 & 1,00 & 8,54 \\
\hline Mediana & 252,00 & 252,00 & 7,00 & 0,00 & 7,00 \\
\hline d.p. & 115,07 & 109,43 & 7,27 & 1,73 & 7,79 \\
\hline
\end{tabular}

ano (média $=8,54$, mediana $=7,00$ e d.p. $=7,79$ ), com um mínimo $=0$, máximo $=21$, o que corresponde a $2,7 \%$ reprovações/ano (mínimo $=0$, máximo $=5,2 \%$ ).

Quando analisamos os resultados das inspeções de qualidade com as reprovações dos reagentes imunohematológicos analisados anualmente, conforme a procedência da inspeção (aquisição e durante o uso), podemos notar que a maior taxa de reprovação ocorreu na aquisição do produto (total $=83$, mínimo $=0$, máximo $=21$, média $=7,54$, mediana $=7,00$ e d.p. $=7,27$ ) o que corresponde a $2,4 \%$ do total de reagentes analisados, enquanto apenas 11 $(0,3 \%)$ reagentes foram reprovados durante o uso no período de 10 anos de acompanhamento (mínima $=0$, máximo $=4$, média $=1,00$, mediana $=0$, d.p. $=1,73$ ).

$\mathrm{Na}$ tabela 2 pode-se observar os principais motivos de reprovações dos reagentes analisados, se por motivos técnicos (especificidade, título, hemólise, partículas em suspensão) e/ou incompatibilidade do produto apresentado com descrição técnica (tais como validade, rótulo, bula e ausência do registro no Ministério da Saúde). Constatamos que a principal causa de reprovação dos produtos não está relacionada com a análise técnica do reagente, mas com a incompatibilidade do produto apresentado quando comparado com a descrição técnica $(67,0 \%)$.

Observando as reprovações referentes às análises técnicas dos reagentes imuno-hematológicos, a mais comum causa de reprovação foi referente à especificidade dos reagentes $(17,2 \%)$, seguido por título $(11,7 \%)$, hemólise $(2,1 \%)$ e presença de partículas em suspensão (2,1\%).

Quando analisamos as causas de reprovação por tipo de reagente testado, notamos que os reagentes $\mathrm{Rh}$ foram os mais reprovados $(29,8 \%)$ e, a seguir, os soros para fenotipagem que não $\mathrm{ABO}$ e $\mathrm{Rh}(26,6 \%)$.

\section{Discussão}

O controle de qualidade em imuno-hematologia desempenha uma função importante, pois os reagentes empregados nas provas imuno-hematológicas são produtos biológicos e suscetíveis a fatores que podem modificar a sua qualidade.

Durante os últimos anos, os bancos de sangue vêm objetivando a melhoria dos seus processos e produtos com a implementação de controle de qualidade, visando a padronização e estabelecendo controles efetivos do sistema, o que promove diminuição de erros e aumenta a credibilidade dos resultados dos testes. ${ }^{24}$

Os requisitos mínimos para cada reagente imunohematológicos foram estabelecidos e são constantemente aperfeiçoados seguindo os preceitos da Organização Mundial de Saúde, de outras agências reguladoras, como FDA (Food and Drug Administration) e Conselho Europeu para a produção de reagentes para bancos de sangue, além de atender a exigências peculiares ao Brasil, como a inclusão de 
Tabela 2. Principais motivos de reprovações na inspeção de qualidade de reagentes imunohematológicos, entre janeiro de 1997 e dezembro de 2007, na Fundação Pró-Sangue/ Hemocentro de São Paulo

\begin{tabular}{|c|c|c|c|c|c|c|}
\hline Reagente & Especificidade & Hemólise & Título & $\begin{array}{c}\text { Partícula em } \\
\text { suspensão }\end{array}$ & $\begin{array}{l}\text { Incomp. com } \\
\text { descrição }\end{array}$ & Total \\
\hline $\mathrm{ABO}$ & 5 & 0 & 2 & 0 & 8 & $\begin{array}{c}15 \\
(16,0 \%)\end{array}$ \\
\hline $\mathrm{Rh}$ & 2 & 0 & 4 & 0 & 22 & $\begin{array}{c}28 \\
(29,8 \%)\end{array}$ \\
\hline Soros ${ }^{*}$ & 7 & 0 & 5 & 0 & 13 & $\begin{array}{c}25 \\
(26,6 \%)\end{array}$ \\
\hline $\begin{array}{l}\text { Reagentes } \\
\text { eritrocitários }^{\star *}\end{array}$ & 0 & 2 & 0 & 2 & 9 & $\begin{array}{c}13 \\
(13,8 \%)\end{array}$ \\
\hline Antiglobulina & 1 & 0 & 0 & 0 & 8 & $9(9,6 \%)$ \\
\hline Outros & 1 & 0 & 0 & 0 & 3 & $4(4,2 \%)$ \\
\hline Total & 16 & 2 & 11 & 2 & 63 & 94 \\
\hline$\%$ & $(17,2 \%)$ & $(2,1 \%)$ & $(11,7 \%)$ & $(2,1 \%)$ & $(67,0 \%)$ & $(100 \%)$ \\
\hline média & 2,67 & 0,33 & 1,83 & 0,33 & 10,50 & 8,54 \\
\hline mediana & 1,50 & 0,00 & 1,00 & 0,00 & 8,500 & 7,00 \\
\hline d.p. & 2,73 & 0,82 & 2,23 & 0,82 & 6,47 & 7,27 \\
\hline
\end{tabular}

*Soros para identificação de antígenos não $\mathrm{ABO}$ e Rh.

${ }^{* *}$ Reagentes eritrocitários para tipagem $A B O$ reversa, pesquisa de anticorpos irregulares, identificação de anticorpos irregulares e controle de Coombs.

pelo menos uma hemácia que tenha o antígeno Dia (Diego) na pesquisa e identificação de anticorpos irregulares. ${ }^{19}$ Esses requisitos levam a uma modificação na manufatura de reagentes de glóbulos vermelhos para o mercado brasileiro, fazendo com que tenham qualidade tal que possam detectar também os anticorpos anti-Diego e, com isso, aumentar a segurança transfusional.

A seleção dos reagentes imuno-hematológicos é um processo que necessita ser planejado cuidadosamente, sendo que não somente devem ser examinadas as características técnicas de cada produto, mas também levar em conta o processo de produção, distribuição e suporte técnicocientífico.

É importante observar ainda que a escolha desse reagentes deve ser compatibilizada com os equipamentos e que os resultados obtidos dependem de um número de fatores incluindo a precisão metodológica e dos funcionários (fator humano).

A caracterização dos reagentes sorológicos usados em imuno-hematologia deve ser feita realizando-se testes contra hemácias com perfil antigênico conhecido com a presença e ausência do antígeno em questão antes de sua utilização. Já os testes dos reagentes imuno-hematológicos eritrocitários envolvem testes com soros específicos, muitas vezes difíceis de serem obtidos, e os soros monoclonais têm auxiliado significativamente nesse sentido. Entretanto, para as especificidades contra as quais não há soros monoclonais disponíveis até o momento, as empresas produtoras de reagentes imuno-hematológicos utilizam soros policlonais obtidos a partir de pacientes sensibilizados para o antígeno em questão. Muitas vezes são soros de custo alto, de baixa disponibilidade e de fraca reatividade. Portanto, há limitações para a realização de testes de qualidade em insumos imuno-hematológicos e testes moleculares que possam contribuir para o aprimoramento da análise da qualidade dos reagentes de hemácias.

A análise de DNA é considerada uma metodologia de alto custo quando comparada com os testes de hemaglutinação, no entanto, o desenvolvimento de plataformas automáticas que permitam a análise de grande número de polimorfismos de um único nucleotídeo (SNPs) pode vir a reduzir esses custos além de permitir uma extensa análise simultaneamente. Diferentemente dos soros de fenotipagem, o suprimento de reagentes para análise de DNA não é limitado, podendo ser facilmente adquiridos.

Além do mais, os reagentes eritrocitários para detecção e identificação de anticorpos clinicamente significantes devem expressar importantes antígenos em dose dupla, isto é, os doadores devem ser homozigotos para esses alelos correspondentes. Tradicionalmente, isso tem sido feito pela fenotipagem sorológica, associada à análise da frequência populacional, porém, em várias situações, como para a detecção de zigozidade do antígeno D, isso é impossível. ${ }^{25}$

Enfim, a análise de DNA de alelos de grupos sanguíneos selecionados pode contribuir para o aumento da garantia de qualidade tanto na detecção de anticorpos clinicamente significantes, ao assegurar que determinada hemácia tem realmente expressão em dupla dose de determinado antigeno, quanto na confecção de painéis de hemácias de triagem e de identificação de anticorpos irregulares atendendo aos requisitos das agências reguladoras.

A análise dos dados obtidos no período de 1997 a 2000 permitiu a elaboração de estratégia que acarretou em redução expressiva de reprovação de reagentes imunohematológicos desde então, e levou à conquista de um indicador da qualidade alcançado na nossa instituição, que foi o decréscimo do número de reagentes analisados na fase de aquisição dos reagentes, demonstrando uma otimização no sistema de compras e armazenamento (Tabelas 1 e 2).

A partir de 2000, utilizamos também estratégias para assegurar a qualidade global em laboratórios de análises clínicas, conforme dados obtidos na Conferência realizada em Estocolmo, em 1999. Nessa conferência foi discutida e publicada como consenso uma hierarquia de modelos que deveriam ser aplicados em laboratórios. ${ }^{26}$ 
A solicitação de reavaliação dos soros utilizados durante o uso demonstra um avanço considerável ao longo da última década (Tabela1). O maior número de reagentes reprovados ocorreu nos primeiros anos de implantação do Laboratório de Controle de Qualidade em Imuno-hematologia devido à fase de implementação, decrescendo ao longo dos anos, demonstrando uma alta confiabilidade nos resultados das análises executadas pelo controle de qualidade prévio. Esse fator de confiabilidade gerado só é possível, atualmente, devido ao processo envolvido na qualidade de reagentes imuno-hematológicos, desde a aquisição de produtos com melhor qualidade, aperfeiçoamento das descrições técnicas, transporte e armazenamento adequado com temperatura controlada, bem como elaboração de procedimentos operacionais padronizados.

É extremamente importante o treinamento e a implementação de programas de educação continuada para todos os envolvidos, desde a elaboração da descrição dos reagentes a serem adquiridos até a inspeção e reanálise por ocasião do uso de reagentes pré-aprovados. ${ }^{27}$ Essas medidas contribuem para que a variação intra e interprofissional na realização dos testes imuno-hematológicos seja minimizada. ${ }^{28}$

A relevância da implementação do controle de qualidade em imuno-hematologia pode ser avaliada quando se observa a redução significativa de reprovação dos reagentes imunohematológicos quer por ocasião de sua aquisição, quer durante o uso. Com a análise periódica das causas de reprovação foi possível o aprimoramento do processo de aquisição desse insumos, contribuindo para o constante aperfeiçoamento desse sistema.

Uma análise interessante é a observação do motivo das reprovações dos reagentes imuno-hematológicos (Tabela 2). O principal motivo das reprovações foi referente à incompatibilidade do produto apresentado com a descrição técnica, mostrando que há necessidade de aperfeiçoamento constante não somente na manufatura, mas na adequação da apresentação do produto para que esteja em conformidade com o exigido pela legislação brasileira e que a implementação do controle de qualidade em imuno-hematologia possa interferir na qualidade de produção dos reagentes imunohematológicos.

A taxa de reprovação de reagentes imuno-hematológicos pode ser comparadas com a de outras instituições. Nossos resultados quanto à reprovação de reagentes imunohematológicos são muito inferiores aos observados pelo Centro Nacional de Referência de Grupos Sanguíneos na França, em 1998, que identificou 2,26\% reagentes ABO nãoconformes, $1,88 \%$ dos $\mathrm{Rh}, 2,4 \%$ dos reagentes de antiglobulina e $15,02 \%$ dos soros para fenotipagem eritrocitária que não ABO e Rh. Em 2004, com a implementação das diretivas europeias para os dispositivos médicos para uso in vitro, houve uma redução expressiva nessas reprovações, sendo constatado que apenas $1,4 \%$ dos reativos Rh estavam abaixo dos requisitos descritos de qualidade. ${ }^{29}$
Dentre as principais causas de reprovação, temos a incompatibilidade com a descrição, isto é, quando da solicitação de reagentes monoclonais foram apresentados policlonais, por exemplo, ou no caso de reagentes eritrocitários, na solicitação de painel com no mínimo 11 hemácias, foram apresentados conjuntos com 8 hemácias e sem a presença da hemácia $\mathrm{Di}(\mathrm{a}+)$. Na análise dos dados referentes ao ano 2000, constatamos que a introdução no País de outros produtores de insumos imuno-hematológicos contribuiu para o elevado número de reprovações observados naquele ano, em especial por não atenderem ao disposto no Código de Defesa do Consumidor.

Graças também à introdução de um número cada vez maior de reagentes monoclonais, a qualidade dos reativos também foi aprimorada, uma vez que as variações biológicas desses insumos quanto à especificidade (uma vez escolhido e bem caracterizado um clone) são praticamente nulas. Devese lembrar que a escolha dos clones utilizados para a produção de soros monoclonais deve ser criteriosa, dada a necessidade de reconhecimento das inúmeras variantes eritrocitárias de grupos sanguíneos. ${ }^{30}$

O aperfeiçoamento do sistema de controle da qualidade antes da utilização dos reagentes é de extrema importância. Quando esse sistema é acompanhado de um controle retroativo, garante rastreabilidade em qualquer fase posterior à liberação, tanto dos reativos, como também avaliação das técnicas empregadas estão sendo utilizadas de forma coerente com normas de qualidade preestabelecidas.

Podemos concluir que, ainda que as técnicas moleculares venham no futuro a aumentar as garantias de qualidade na produção de reagentes imuno-hematológicos, até o momento, para a implantação do controle de qualidade em Imuno-hematologia em serviços hemoterápicos rotineiros, não é necessário uso de reagentes ou equipamentos altamente especializados, pois os mesmos são utilizados na rotina laboratorial, como também não envolvem alta complexidade na execução das análises. Podemos enfim considerar que a implementação do controle de qualidade em imuno-hematologia contribui para o aumento da segurança transfusional e é factível de realização nos mais diferentes níveis de complexidade dos serviços hemoterápicos.

\section{Abstract}

Transfusion medicine has the purpose of guaranteeing the quality and quantity of blood, blood derivatives and services offered to the community. Thus, the analysis of serological reagents is critical in pre-transfusion testing and, consequently, reliable transfusions. A constant improvement in the tests that analyze the quality of reagents and equipment utilized is the responsibility of quality control. This paper aims at presenting the results and experience achieved over 10 years in the Department of Quality Control in Immunohematology at Fundação Pró-Sangue / Hemocentro de São Paulo. In the period of January 1997 to December 2007 we carried out analyses of 3,417 serological reagents at acquisition and/or during their use. 
The analyses included from visual inspection to specific laboratory tests for each kind of reagent. Of the 3,417 lots analyzed (mean = 310/year, median = 252/year), 94 (2.7\%-median=8.54/year) failed the tests. From 2004 to date, once the reagents were approved, none failed during use. The implementation of a quality control system with standardized techniques is important for the adequate utilization of serological reagents. This system accomplished by retroactive control of the reagents, contributed to the safety and reliability of results in immunohematology testing. Rev. Bras. Hematol. Hemoter. 2009;31(3):160-165.

Key words: Quality; hemotherapy; blood groups; transfusion; antiglobulin.

\section{Referências Bibliográficas}

1. Holburn AM, England JM. The UK national external quality assessment scheme in blood group serology. Compatibility testing 1979-1980: trends and performance in relation to practice in antiglobulin testing. Clin Lab Haematol. 1982;4(2):155-67.

2. Anvisa. Serviços de Hemoterapia: portaria no. 2135 de 22 de dezembro de 1994. Disponível: htt://www.anvisa.gov.br/sangue/ legis/portarias.htm. Acessado em 01 dezembro de 2007.

3. Anvisa. Serviços de Hemoterapia: portaria ${ }^{\circ} 121,24$ de novembro de 1995. Disponível: http://www.anvisa.gov.br/sangue/legis/ portarias.htm. Acessado em 01 dezembro de 2007.

4. Anvisa. Serviços de Hemoterapia: portaria $\mathrm{n}^{\circ} 127,08$ de dezembro de 1995. Disponível: http://www.anvisa.gov.br/sangue/legis/ portarias.htm. Acessado em 01 dezembro de 2007.

5. Anvisa. Serviços de Hemoterapia: lei 10.205 de 21 de março de 2001. Disponível: http://www.anvisa.gov.br/sangue/legis/leis.htm. Acessado em 01 dezembro de 2007.

6. Anvisa. Serviços de Hemoterapia: portaria ${ }^{\circ} 262$ de 5 de fevereiro de 2002. Disponível: http://www.anvisa.gov.br/sangue/legis/ portarias.htm. Acessado em 01 dezembro de 2007.

7. Anvisa. Serviços de Hemoterapia: resolução RDC n 153, 14 de Junho de 2004. Disponível:http://www.anvisa.gov.br/sangue/legis/ sangue_componentes.htm\#resoucoes. Acessado em 01 dezembro de 2007.

8. Anvisa. Serviços de Hemoterapia: Sangue e Hemoderivados Meta Mobilizadora Nacional. Disponível: http://www.anvisa.gov.br/ sangue/meta/meta5.htm. Acessado em 01 dezembro de 2007.v

9. Morganti L, Bellis T, Andreoli MA, Zago-Novaretti MCZ, DorlhiacLlacer PE, Chamone DAF. Quality control in blood group reagents: a brazilian experience. Vox Sang 1998;74(s1):1634.

10. Ruiz AS, Domingues AE, Dorlhiac-Llacer PE, Charmone DAF e Novaretti MCZ. A importância da padronização e inspeção de qualidade dos reagentes imuno-hematológicos. Boletim da Sociedade Brasileira de Hematologia e Hemoterapia 2003; 25(S2), 679:207.

11. Bueno VJ, Novaretti MCZ, Bonifácio SL, Dorlhiac-Llacer PE, Chamone DAF. A importância da reavaliação qualidade de reagentes imuno-hematológicos durante o uso. Rev Bras Hematol Hemoter. 2005;27(S2)652:241.

12. de Almeida Neto C, McFarland W, Murphy EL, Chen S, Nogueira FA, Mendrone A Jr, et al. Risk factors for human immunodeficiency virus infection among blood donors in Sao Paulo, Brazil, and their relevance to current donor deferral criteria. Transfusion. 2007; 47(4):608-14.

13. Canada. Canadian General Standards Board. CGSB106.4-M86. 1976. p.p.1-38.

14. Frey-Wettstein M, Barandun S, Bucher U, Butler R, Metaxas M. Diebluttransfusion ein Vademecum. Munchen: Karger; 1986: 24:236.
15. Code of Federal Regulations. Additional standards for diagnostic substances for laboratory. Food and Drugs Administration. Parts 600 to 799. Washington: US Government Printing Office; 2001: $110-121$.

16. Grinover ap. código de defesa do consumidor. Disponível: http:// www.idec.org.br/ cdc.asp. Acessado em 01 dezembro de 2007.

17. Suarez LB, Rivero RJ, Perez N. Reactivo hemoclasificador monoclonal cubano heom-cim anti-a: Estudio de estabilidad. Rev Cubana Hematol Inmunol Hemoter 1999;15(2):132-136.

18. Novaretti MCZ, Bueno VJ, Dorlhiac-Llacer PE, Chamone DAF. controle de qualidade interno de reagentes em imuno-hematologia - aspectos práticos. Rev Bras Hemat Hemoter. 2002;24(4):270285.

19. US Food and Drug Administration. Rockville Pike, Bethesda: Additional standards for diagnostic substances for laboratory tests; April 1,2002; 113-115; Docket $\mathrm{N}^{\mathrm{o}} 21 \mathrm{crf660.28}$.

20. US Food and Drug Administration. Rockville Pike, Bethesda: Recommended methods for blood grouping reagents evaluation; 1992; 1-53; Docket No 84S-0181.

21. Thorpe SJ, Fox B, Heath AB, Scott M, de Haas M, Kochman S, et al. International standards for minimum potency of anti-A and anti-B blood grouping reagents: evaluation of candidate preparations in an international collaborative study. Vox Sang. 2006;91(4):336-44.

22. Brecher M. AABB Technical Manual. $15^{\text {th }}$ ed. Bethesda, Maryland: American Association of Blood Banks; 2005:729.

23. Issitt PD, Anstee DJ. Applied blood group serology. $4^{\text {th }}$ ed. Durham: Montgomery Scientific Publications; 1998:1208.

24. Franco E. El control de la calidad de los análisis inmunohematológicos en la Region de las Américas. Rev Panam Salud Publica 2003;13(2-3):176-182.

25. Hult A, Hellberg A, Wester ES, Olausson P, Storry JR, Olsson ML. Blood group genotype analysis for the quality improvement of reagent test red blood cells. Vox Sang. 2005;88(4):265-70.

26. Strategies to set Global Quality Specifications in Laboratory Medicine. Stockholm. Clin Med 1999;45:321-3.

27. Dhatt GS, Agarwal MM, Bishawi B, Gill J. Implementing the Stockholm Conference hierarchy of objective quality criteria in a routine laboratory. Clin Chem Lab Med. 2007;45(4):549-52.

28. Petersen PH, Fraser CG, Jørgensen L, Brandslund I, Stahl M, Gowans E. Combination of analytical quality specifications based on biological within- and between-subject variation. Ann Clin Biochem. 2002;39(Pt 6):543-50.

29. Rouger P, Ansart-Pirenne H, Le Pennec PY. Annual Report 2004 - French National Reference Centre for Rare Blood Groups and Immunohaematology (CNRGS). Transfus Clin Biol. 2005; 12(4): 345-52.

30. Noizat-Pirenne F, Le Pennec PY, Rouger P. Les contrôles de lots de réactifs au Centre national de référence des groupes sanguins (CNRGS). Données de lannée 1998. Transfus Clin Biol. 1999; 6(3):195-200

Avaliação: Editor e dois revisores externos

Conflitos de interesse: sem conflito de interesse

Recebido: 04/08/2008

Aceito após modificações: 24/11/2008 